\title{
Pengurusan identiti bangsa dalam trilogi karya Hamka: Suatu pengenalan
}

\author{
${ }^{1}$ Fathin Noor Ain Ramli; ${ }^{2}$ Azhar Wahid \\ ${ }^{1.2}$ Fakulti Bahasa dan Komunikasi, Universiti Pendidikan Sultan Idris \\ laennramli@gmail.com, 2azhar@fbk.upsi.edu.my
}

DOI: https://doi.org/10.37134/peradaban.vol14.4.2019

\begin{abstract}
ABSTRAK
Penulisan makalah ini bertujuan memperlihatkan penggunaan prinsip pengurusan untuk mengetahui prinsip yang terdapat dalam pengurusan identiti bangsa yang berasaskan daripada penyelidikan Pengurusan Identiti Bangsa dalam Trilogi Karya Hamka. Antara objektif kajian ialah mengenalpasti pengurusan identiti bangsa Melayu dan melihat kesesuaian Teori Teksdealisme dalam menganalisis pengurusan identiti bangsa yang terdapat dalam trilogi novel Hamka iaitu Tenggelamnya Kapal Van Der Wijck, Merantau Ke Deli dan Di Bawah Lindungan $K a$ 'bah. Penelitian yang berbentuk tekstualiti ini adalah penelitian yang berasaskan kajian kualitatif. Teori Teksdealisme telah dijadikan sebagai landasan utama dan digabungkan bersama 14 Prinsip Asas Pengurusan oleh Henry Fayol. Empat prinsip Teori Teksdealisme iaitu prinsip kehadiran, prinsip pelanggaran, prinsip pengukuhan dan individualisme diaplikasikan bagi melihat proses pembentukan identiti bangsa dalam novel tersebut. Manakala 14 Prinsip Asas Pengurusan oleh Henry Fayol dijadikan teori sokongan untuk menganalisis pembentukan identiti bangsa Melayu. Kajian ini merupakan kajian kualitatif yang menggunakan kaedah kepustakaan dan kaedah analisis teks kandungan (content analysis). Kaedah ini akan mengumpul dan menganalisis data daripada tiga buah novel karya Hamka iaitu Tenggelamnya Kapal Van Der Wijck, Merantau ke Deli dan Di Bawah Lindungan Ka'bah. Watak dan perwatakan tonggak utama diteliti dalam merungkai pengurusan identiti yang telah diketengahkan oleh Hamka. Kajian ini diharapkan dapat memberi manfaat kepada golongan sastera terutamanya golongan-golongan yang terlibat dalam aspek pengurusan sastera. Mereka bukan sahaja memerlukan pengetahuan dalam bidang kesusasteraan semata-mata, tetapi juga pengetahuan yang mendalam dalam bidang pengurusan untuk mencapai objektif penubuhan masing-masing.
\end{abstract}

Kata Kunci: Pengurusan, Identiti, Bangsa, Melayu, Kesusasteraan.

\begin{abstract}
The purpose of this paper is to demonstrate the application of principle management in order to find out the principles of identity management based on the research of Identity Management of the Nation in the Hamka's Trilogy. Among the objectives of the study were to determine the identity of the Malays and suitability of Textdealism theory in analysing the national identity management contained in the trilogy of Hamka's novels which are Tenggelamnya Kapal Van Der Wijck, Merantau Ke Deli and Di Bawah Lindungan Ka'bah. This textual research is qualitative research based. The theory of Textdealism has been applied as the main course theory and is combined with 14 Principles of Management by Henry Fayol. Four principles of Textdealism Theory; the principle of presence, the principle of violation, the principle of reinforcement and individualism are applied to see the process of forming a national identity in the novel. While 14 Basic Principles of Management by Henry Fayol pledged as a supporting theory to analyse the formation identity of the Malay. This study is a qualitative study that using library and content analysis method. These methods will collect and analyse data from three novels of Hamka's works: Tenggelamnya Kapal Van Der Wijck, Merantau ke Deli dan Di Bawah Lindungan Ka'bah. The main character and characteristic of main actors are examined in dismantling the identity management that highlighted by Hamka. This study is expected to benefit the literary expert especially those involved in the literature management. They not only need knowledge in the field of literature, but also in-depth knowledge in the field of management to achieve their objectives.
\end{abstract}

Keywords: Management, Identity, Nation, Malay, Literature. 


\section{PENGENALAN}

Pengurusan merupakan aspek yang penting bagi sesebuah organisasi tidak kira sama ada organisasi yang terbentuk bagi mencapai sesuatu objektif, misi ataupun visi mahupun juga organisasi sesebuah anggota masyarakat. Ia penting bagi memastikan segala gerak kerja, pembentukan serta perlaksanaan sesebuah rancangan, struktur orgnisasi yang terbentuk adalah berada pada landasan sepatutnya sebagaimana yang diinginkan. Secara umumnya, pengurusan dapat dikatakan sebagai proses bagi mencapai matlamat sesebuah organisasi bagi mencapai matlamat dengan cara yang berkesan dan cekap. Menurut Daft (1997), pengurusan dilakukan melalui proses perancangan, pengorganisasian, kepimpinan dan pengawalan sumber-sumber organisasi. Perancangan menurut Certo (1997) yang dipetik daripada Aizzat Mohd Nasurdin, Intan Osman, Zainal Ariffin Ahmad (2006) adalah merupakan proses bagaimana sistem pengurusan organisasi boleh mencapai matlamatnya. Ini menjelaskan bahawa sesebuah organisasi itu merangka satu kerangka tindakan yang bakal diambil bagi membolehkan target yang ditetapkan oleh organisasi mereka tercapai sebagaimana yang diinginkan.

Pengorganisasian pula adalah segala tindakan bagi mencapai matlamat yang diagihkan kepada seluruh anggota organisasi mengikut peranan yang telah ditetapkan. Menurut Bartol dan Martin (1994) mendefinisikan pengorganisasian sebagai proses mengagihkan dan menyusun sumber manusia dan bukan manusia supaya pelan dapat dilaksanakan dengan jayanya. Manakala prinsip kepimpinan, menurut Robbins and Coutler (2005) mentakrifkan kepimpinan sebagai proses yang mempengaruhi kumpulan ke arah pencapaian matlamat. Bagi pengawalan pula merupakan fungsi atau peranan terakhir dalam bidang pengurusan. Menurut Certo (1997) ia merupakan usaha yang sistematik untuk membandingkan prestasi dengan piawaian, pelan atau objektif yang telah ditetapkan sebelumnya untuk menentukan sama ada prestasi adalah konsisten dengan piawaian ataupun prestasi tersebut perlu diperbaiki.

Sehubungan itu, ketertiban dan susun atur yang baik dalam aspek pengurusan tidak kira dalam apa jua bidang, organisasi mahupun dalam pengendalian sesuatu program memainkan peranan yang sangat penting. Bagi memastikan segala matlamat ataupun objektif sesebuah organisasi mahupun bidang itu tercapai, pengurusan yang cekap haruslah dititikberatkan. Kepincangan dalam aspek pengurusan jelas bakal memberi kesan sama ada bagi jangka masa panjang ataupun jangka masa pendek. Makanya, penerapan disiplin pengurusan dalam bidang Kesusasteraan Melayu dilihat dapat memastikan bidang ini terus berkembang dan sentiasa bergerak seiring dengan arus modenisasi negara. Secara dasarnya pengurusan sastera boleh dibahagikan kepada dua iaitu pengurusan yang berhubung kait dengan operasi sesebuah organisasi yang meletakkan sastera sebagai teras manakala yang keduanya adalah pengurusan yang terdapat dalam sesebuah teks sastera (Majlis Peperiksaan Malaysia, 2014).

Menurut Ismail Ahmad (1990) yang dipetik dari Sukatan Pelajaran STPM Baharu 922 Kesusasteraan Melayu Komunikatif (2014) menyatakan bahawa pengurusan sastera ialah mereka yang bertugas di sesebuah institusi untuk mengembangkan sastera, termasuk institusi penerbitan sastera juga adalah ejen. Beliau turut menyatakan bahawa kerja utama yang menjadi fokus adalah mengembang dan memajukan kesusasteraan melalui organisasi atau badan yang tertentu. Individu dan organisasi ini juga bertanggungjawab dalam memikir dan juga merancang bagi membina dan mengembangkan kesusasteraan, penulis dan karya. Seseorang penulis mungkin juga terlibat dalam aspek pengurusan apabila beliau sendiri terlibat dalam sesebuah organisasi ataupun kumpulan yang bertanggungjawab bagi meletakkan bidang sastera pada satu tahap atau matlamat yang ditetapkan seperti Persatuan Penulis Budiman Malaysia, Persatuan Karyawan Perak dan Persatuan Penulis dan Peminat Sastera Perak Malaysia. Kemahiran dan pengetahuan tentang bidang pengurusan sedikit sebanyak membantu mereka dalam mentadbir urus organisasi yang mereka tubuhkan dengan sebaiknya bagi memastikan penubuhan badan-badan ini memainkan peranan yang sewajarnya untuk membantu pihak berwajib iaitu pihak kerajaan seperti Kementerian Pelancongan, Kesenian dan Kebudayaan memartabatkan bidang Kesusasteraan di Malaysia.

Selain itu, pengurusan sastera juga dapat dilihat di dalam teks sastera. Pengenalan pendekatan pengurusan di dalam bidang Kesusasteraan Melayu di tanah air oleh Profesor Mohammad Mokhtar Abu 
Hassan membuktikan bahawa disiplin ini amat bersesuaian dalam bidang kritikan sastera moden. Beliau telah membentangkan pendekatan baharu ini sebagai salah satu metod baharu dalam penelitian sastera ketika menghadiri Seminar Himpunan Ilmuwan Sasterawan Melayu (HISMA) pada tahun 2013 di Universiti Pendidikan Sultan Idris melalui kertas kerjanya yang bertajuk "Pendekatan Pengurusan: Satu Metode dalam Dunia Kritikan" (Mohamad Zubir Ismail \& Mohamad Mokhtar Hassan, 2017). Pendekatan ini telah mengenengahkan lima prinsip asas pengurusan iaitu Prinsip Perancangan, Prinsip Kepimpinan, Prinsip Pengorganisasian, Prinsip Penstafan dan Prinsip Pengawalan. Kelima-lima prinsip ini diterapkan bagi menganalisis struktur teks sesebuah karya iaitu meliputi watak, perwatakan, nilai, isu, persoalan, latar dan juga pemikiran yang dibawa oleh pengarang di dalam karya mereka.

Ketika membentang metod pendekatan moden ini, Mohammad Mokhtar Abu Hassan telah mengambil beberapa cerita sastera rakyat iaitu Sang Kancil dan Buaya, Lebai Malang serta Di Sebalik Tirai Makna sebagai batasan kajian untuk mengaplikasikan pendekatan ini. Berdasarkan dapatan dan analisis yang dijalankan oleh beliau, kelima-lima prinsip yang terdapat dalam pengurusan sastera sememangnya sangat bersesuaian bagi meneliti teks-teks sastera. Mengaplikasikan disiplin pengurusan dalam bidang sastera di tanah air dilihat mampu memberikan kesan positif apabila satu pemikiran aliran baharu ini dapat memberikan kelainan dan memeriahkan lagi penelitian terhadap karya-karya sastera pada masa yang akan datang. Walaupun medium sastera bersilih ganti, iaitu bermula daripada tradisi lisan kepada tradisi tulisan dan kini kepada medium alternatif, namun aspek pengurusan seharusnya tidak terpinggir dan perlu diberi perhatian dan diberikan keutamaan (Mohamad Zubir Ismail, Sara Beden, Mohamad Mokhtar Hassan, 2015).

Kesinambungan daripada pengenalan pendekatan pengurusan dalam bidang Kesusasteraan Melayu, Kementerian Pendidikan Malaysia telah menggubal semula Sukatan Pelajaran Kesusasteraan Melayu Komunikatif dengan mengemas kini tajuk, kandungan dan kemahiran agar selari dengan perkembangan semasa. Sukatan yang baharu ini bertujuan mendedahkan kepada calon pada peringkat prauniversiti berkaitan dengan penghayatan karya; sastera dan pembangunan; kreativiti, pengurusan dan multimedia di samping memberi penekanan bagi meningkatkan kemahiran menulis, mencari dan menganalisis maklumat, menyelesaikan masalah dan komunikasi secara berkesan. Antara objektif sukatan pelajaran baharu ini adalah bagi membolehkan para pelajar;

(a) mengapresiasi karya kesusasteraan;

(b) mengkaji dan menelusur ilmu kesusasteraan serta penerapan ilmu bantu;

(c) menghuraikan konsep sastera dan pembangunan meliputi pembangunan insan, masyarakat, dan negara berasaskan teks sastera terpilih;

(d) menghasilkan karya kreatif;

(e) menyunting karya kreatif;

(f) menguasai dan menghuraikan prinsip pengurusan dalam organisasi sastera;

(g) mengkaji dan memahami ilmu pengurusan dalam karya; dan

(h) menguasai dan mengaplikasikan elemen multimedia dalam teks sastera terpilih.

Kandungan sukatan pelajaran baharu ini terdiri daripada tiga bahagian iaitu penghayatan karya, sastera dan pembangunan serta kreativiti, pengurusan dan multimedia. Pada penggal ketiga, calon akan mempelajari prinsip asas pengurusan (perancangan, pengorganisasian, tenaga kerja ataupun staffing, kepimpinan dan kawalan) di mana pada akhir sesi pembelajaran calon dapat menjelaskan maksud dan konsep asas pengurusan dan menghuraikan prinsip asas pengurusan organisasi. Seterusnya calon harus menerapkan prinsip asas pengurusan ini ke dalam teks dengan mengenalpasti unsur pengurusan daripada teks kajian serta menganalisis asas pengurusan dalam organisasi yang wujud dalam teks kajian. Organisasi sastera pula mendedahkan calon kepada aspek perancangan kerja dalam organisasi sastera dan menghuraikan aspek pengurusan projek seperti seminar, kursus, pertandingan serta pementasan. Ini jelas membuktikan bahawa kepentingan bagi memberikan penekanan kepada aspek pengurusan sastera itu sendiri harus dipupuk sejak generasi muda lagi supaya bidang Kesusasteraan Melayu dapat dilestarikan melewati arus pemodenan semasa dengan bermula dari lapisan awal insititusi pendidikan iaitu di sekolah. 


\section{TINJAUAN LITERATUR}

Berdasarkan penelitian terhadap kajian lalu, keterbatasan dalam meneroka dan mendapatkan kajian yang berkaitan ataupun membincangkan tentang identiti bangsa Melayu diakui sangatlah terhad. Adapun antara kajian tersebut tidaklah secara khusus membincangkan identiti dengan terperinci. Maka, sebarang kajian terhadap masyarakat atau bangsa yang terdapat yerdapat dalam negara dijadikan sebagai rujukan. Kajian yang dijalankan oleh Wan Sallha Yusoff, Nurul Syazwani, Ahmad Fahmi Mahmood dan Noor Asliza Abdul Rahim daripada Universiti Malaysia Perlis bertajuk Faktor-faktor Yang Mempengaruhi Penentuan Identiti Diri Remaja Melayu adalah bagi mengetahui faktor-faktor yang mempengaruhi remaja lelaki dan perempuan Melayu bagi menentukan identiti mereka. Responden yang terlibat adalah daripada kalangan pelajar bidang Kejuruteraan dan Perniagaan yang menuntut pada tahun satu sehingga tahun empat, berbangsa Melayu dan berumur dalam linkungan 19 hingga 25 tahun. Hasil kajian ini menyatakan bahawa terdapat hubungan yang positif antara faktor-faktor yang mempengaruhi ibu bapa, ekonomi, rakan sebaya, pendidikan dan media massa bagi membentuk identiti pelajar lelaki Melayu manakala bagi pelajar perempuan Melayu, hubungan positif hanyalah ditunjukkan antara faktor-faktor pengaruh ibu bapa, pendidikan dan ekonomi dalam membentuk identiti pelajar perempuan Melayu.

Kajian seterusnya adalah bertajuk Identiti Budaya dan Bahasa Etnik Melayu Thesaban Takbai, Selatan Thailand: Satu Analisa Fenomenologi oleh Hasni Zakaria dan Novel Lyndon dari Universiti Kebangsaan Malaysia. Tujuan utama adalah bagi memahami identiti bahasa dan budaya kumpulan etnik minoriti. Kajian yang menggunakan paradigm penyelidikan fenomenologi yang mana menfokuskan pemahaman kelompok etnik Melayu Selatan Thailand di Thesaban Takbai, Narathiwat dalam pembentukan identiti etnik berdasarkan pandangan dunia mereka. Responden yang terlibat adalah orang individu etnik Melayu Selatan Thailand di Thesaban Takbai, Narathiwat, Thailand. Berdasarkan kajian yang telah dijalankan ini, etnik Melayu Thesaban Takbai Selatan Thailand mengekalkan budaya Melayu Patani dari segi aspek berpakaian dan penggunaan nama. Responden juga berpendapat bahawa identiti bahasa menunjukkan mereka sangat bertoleransi terhadap bahasa Thai iaitu Bahasa Kebangsaan di Thailand. Kajian ini juga menjelaskan bahawa pemerintah di Thailand seharusnya mengambil kira kepentingan etnik minoriti yang terdapat di negara mereka dan juga mengamalkan pentadbiran yang bersifat dari atas ke bawah melalui pendekatan asimilasi yang mengenepikan golongan minoriti.

Mohamad Saleeh Rahamad (2012) menerusi makalahnya yang bertajuk Pewacanaan Identiti Bangsa Dalam Sastera Selepas Merdeka: Pengalaman Malaysia membincangkan corak oksidentalisme dalam karya sastera terpilih yang terdapat pada zaman awal kemerdekaan Malaysia iaitu ketika pemerintahan Perdana Menteri yang pertama, Tunku Abdul Rahman Putra Al Haj. Berdasarkan penelitian yang telah dilakukan, oksidentalisme ataupun pewacanaan identiti bagi masyarakat peribumi Timur dan Barat ternyata masih mempunyai sikap binarisme yang mutlak iaitu menyerupai wacana orientalisme. Sikap yang objektif dengan hanya meruntuhkan legasi keagungan Barat masih dimiliki oleh pengarang Timur dalam usaha mereka mempertahankan kebaikan negara Timur sahaja dan bukannya memburuk atau mengusai Barat secara total. Tujuan sebenar pewacanaan identiti Timur adalah bagi mengembalikan kehormatan bangsa dan keburukan serta kebaikan imej Barat yang diceritakan adalah masih dalam keadaan terkawal dan seimbang.

Bagi Farahanna Abd Razak, Ida Baizura Bahar dan Rosli Talif (2016) melalui kajian yang bertajuk Emerging Patterns of Bangsa Malaysia in Anthony Burgess' Time for a Tiger membincangkan tentang corak pembinaan Bangsa Malaysia yang terdapat dalam sebuah novel yang bertajuk Time For A Tiger karya Anthony Burgess pada tahun 1965. Kajian ini telah memperlihatkan bahawa sememangnya terdapat corak baharu Bangsa Malaysia yang digambarkan melalui gabungan watak-watak yang datangnya daripada pelbagai etnik iaitu daripada kalangan orang Melayu, Cina dan India berdasarkan perlaksanaan dasar-dasar kerajaan, pendidikan, perubahan minda dan peribadi, penghakiman, patriotisme dan peranan penyatuan monarki. Selain itu, kajian ini juga membuktikan bahawa corak yang menyokong kepada pembinaan bangsa Malaysia adalah melalui sikap bertoleransi. 
Kajian yang telah dijalankan oleh Lia Dwi Purwanti (2016) pada peringkat sarjana yang bertajuk NilaiNilai Pendidikan Sosial Dalam Novel Tenggelamnya Kapal Van Der Wijck karya Buya Hamka pula membincangkan nilai-nilai pendidikan sosial yang terdapat dalam novel Tenggelamnya Kapal Van Der Wijck oleh Hamka. Hasil kajian telah membuktikan tiga aspek utama iaitu nilai-nilai pendidikan sosial yang terdapat dalam novel Tenggelamnya Kapal Van Der Wijck adalah nilai kasih sayang, tanggungjawab dan keserasian hidup. Selain itu juga, karakter watak utama yang harus dicontohi dalam karya ini adalah sikap dan perilakunya terhadap Allah SWT, diri sendiri, keluarga, masyarakat dan bangsa serta kepada alam sekitar. Kajian ini juga mendapati bahawa implikasi pendidikan sosial dalam novel ini dapat membuka mata hati pembaca dan seterusnya mengaplikasikannya dalam pendidikan agama Islam. Novel ini ternyata memiliki nilai pendidikan yang tinggi sehingga para pembaca digesa untuk menyerap dan mengambil nilai-nilai yang terkandung termasuk nilai sosial. Nilai-nilai ini dapat memupuk individu itu memiliki karakter dan peribadi yang baik.

Tinjauan literatur seterusnya meneliti kepada kajian lalu terhadap karya-karya Hamka yang mana dilihat mampu menyumbang kepada proses pengukuhan kajian ini. Muhammad Hilmi Jalil dan Fakhrul Adabi Abdul Kadir (2012) menerusi tajuk kajian mereka yang bertajuk Comprehensive Human Development Through Physical and Spiritual: Studies on the Novel "Tenggelamnya Kapal Van Der Wijck" pula membincangkan bentuk pembangunan manusia yang mana boleh dipupuk melalui bidang penulisan. Dalam kajian ini, ia cuba untuk mengenal pasti elemen-elemen perkembangan manusia yang terkandung di dalam novel karya Hamka iaitu Tenggelamnya Kapal Van Der Wijck. Sepuluh domain unsur pembangunan manusia yang digambarkan oleh Al-Banna telah diguna pakai iaitu badan yang sihat, akhlak yang baik, berpengetahuan tinggi, kepercayaan pada diri sendiri, keimanan, melaksanakan ibadah dengan betul, kawal diri, menguruskan masa dengan efektif, individu yang berdisiplin dan individu yang menyumbang kepada masyarakat. Hasil dapatan telah membuktikan bahawa novel Tenggelamnya Kapal Van Der Wijck adalah merupakan bahan bacaan yang sangat sesuai bagi pembaca untuk digunakan dalam proses pembangunan manusia.

\section{PERMASALAHAN KAJIAN}

Penerapan aspek pengurusan dalam pembangunan dan pembentukan identiti sesebuah negara melalui karya sastera adalah sangat terhad. Kesedaran kepentingan penerapan terhadap disiplin pengurusan hanyalah dilihat dan difokuskan kepada pembangunan dan kemajuan sesebuah organisasi syarikat atau pertubuhan sahaja tetapi tidak diberikan penekanan kepada pembangunan organisasi masyarakat itu sendiri. Selain itu, kesedaran akan pembangunan organisasi masyarakat sebagai ciri-ciri yang mencerminkan identiti masyarakat dan juga sesebuah bangsa adalah masih cetek. Justeru itu, kesedaran bagi penyelidikan dalam aspek pengurusan sastera ataupun kesusasteraan itu sendiri adalah sangat kurang dan boleh dikatakan tidak menjadi perhatian dan tidak mampu menarik minat para penyelidik.

Ketika proses sesebuah negara mengejar arus modenisasi dan taraf negara maju, penumpuan adalah lebih berat diberikan kepada pembangunan dari segi sains dan teknologi secara mutlak. Hal ini menjadikan anggota masyarakat lebih tertumpu kepada bidang sains dan teknologi dalam kehidupan seharian dan penerapan disiplin pengurusan hanyalah berfokuskan kepada organisasi syarikat sahaja bagi mencapai target yang ditetapkan. Oleh itu, kebanyakan organisasi syarikat mengaplikasikan segala kemudahan dan manfaat sains dan teknologi secara total dalam segala operasi mereka. Sememangnya tidak dapat disangkal bahawa ia menjadikan bidang pengurusan semakin hari semakin cekap dan efektif serta terus berkembang. Namun begitu, secara tidak langsung kebimbangan terhadap mengimbangi keperluan rohani tidak ditekankan yang akhirya menyebabkan pembentukan insaniah itu terabai sedikit demi sedikit.

Setiap individu atau anggota dalam masyarakat boleh dikatakan adalah pengurus kerana pada hakikatnya setiap hari mereka sudah menjalankan tanggungjawab sebagai seorang pengurus yakni apabila mereka menguruskan kehidupan masing-masing, keluarga dan juga orang di sekeliling mereka. Ia merangkumi pelbagai aspek seperti aspek kewangan, masa dan rumahtangga. Secara tidak langung 
kita mendapati bahawa kita sebenarnya telah menerapkan asas-asas pengurusan iaitu merancang, mengorganisasi, memimpin dan mengawal. Sebagai contohnya, pada setiap pagi seawalnya kita bangun dari tidur pada setiap hari, kita telah pun menguruskan kehidupan kita sendiri dengan memikirkan apakah perancangan aktiviti yang bakal dilakukan pada hari tersebut. Berdasarkan perancangan itu, kita cuba mengatur masa dengan sebaiknya dan memikirkan cara bagaimanakah memastikan ia terlaksana. Pada akhirnya sudah tentu kita akan meneliti dan melakukan kawalan agar sebarang masalah yang telah terjadi dapat dielakkan dan tidak berulang pada masa akan datang. Jika setiap hari kita melatih diri menguruskan kehidupan dengan sebaiknya dan teratur, secara tidak langsung ia dapat memupuk dan membentuk diri menjadi seorang individu yang mempunyai jati diri yang tinggi. Tidakkah ini boleh dikatakan juga sebagai langkah dalam usaha membentuk identiti individu bahkan masyarakat serta bangsa itu sendiri?

Sebuah bangsa dianggotai oleh masyarakat yang berasalnya individu-individu yang berada dalam kelompok tertentu. Walaupun mungkin berbeza kedudukan geografi dek kerana persempadanan politik dan pemerintahan, tetapi mereka masih menyanjung dan berpegang kepada persamaan yang tertentu yakni adat, agama serta mungkin juga undang-undang yang sama. Menyedari kepentingan bagi membentuk negara dan bangsa yang beridentiti teguh, kerajaan telah meletakkan salah satu dari teras strategik dalam Rancangan Malaysia Ke-11 adalah usaha ke arah pembentukan identiti yang teguh iaitu pada teras ke tiga, Meningkatkan Pembangunan Modal Insan Untuk Negara Maju (Rancangan Malaysia ke Sebelas, 2016). Pembangunan ini dilihat sebagai faktor yang begitu dominan dalam memastikan perkembangan sektor ekonomi negara. Penumpuan bagi teras ketiga ini adalah dalam usaha kerajaan bagi membentuk sebuah negara bangsa yang mempunyai modal insan yang tinggi. Ini telah jelas dinyatakan di dalam perancangan tersebut iaitu;

Pembangunan modal insan merupakan pemboleh penting bagi memacu pertumbuhan ekonomi dan menyokong peralihan semua sektor kepada aktiviti berintensif pengetahuan. Pasaran buruh yang cekap dan berkesan perlu untuk menarik pelaburan bagi membolehkan rakyat mengambil bahagian dalam aktiviti ekonomi dan mendapat manfaat daripada pertumbuhan ekonomi.

(RMK 11 Bab 1 Pertumbuhan Berpaksikan Rakyat, 2016: 9)

Oleh yang demikian, penumpuan kerajaan bagi menyeimbangi kemajuan dan pembangunan negara dibuktikan dengan menyenaraikan pembangunan modal insan sebagai salah satu teras strategik yang sama-sama didokong dan bakal dipandang serius. Apabila meletakkannya sebagai salah satu teras, sudah pasti sebahagian besar bajet dan kewangan negara diperuntukkan oleh kerajaan bagi memastikan kelancaran susun atur segala perancangan yang bakal dijalankan. Salah satunya adalah melalui bidang pendidikan yang mana melalui Pelan Pembangunan Pendidikan Malaysia 2013-2025 (Pendidikan Prasekolah hingga lepas Menengah) atau PPPM yang dilancarkan pada 2013. Matlamat utama adalah untuk melahirkan rakyat Malaysia yang memiliki pengetahuan, kemahiran berfikir secara kritis, kemahiran kepimpinan, kemahiran bahasa, etika dan kerohanian serta identiti nasional untuk berjaya dalam abad ke-21 (RMK 11 Bab 5 Meningkatkan Pembangunan Modal Insan Untuk Negara Maju, 2016: 10). Maka, ia kukuh menjelaskan bahawa kerelevanan bagi menitikberatkan pembentukan identiti yang teguh bagi negara yang sedang meningkat maju menuju Wawasan 2020.

Seterusnya berdasarkan kajian yang dijalankan terhadap aspirasi rakyat Malaysia Pasca 2020, terdapat tiga aspirasi yang telah diketengahkan sebagai dimensi penting iaitu Rakyat, Ekonomi dan Alam Sekitar. Ketiga-tiga dimensi ini adalah berlatarbelakangkan trend global yang dipercayai dapat membina negara Malaysia pada masa hadapan. Sistem Nilai di dalam Dimensi Rakyat telah menggariskan kepentingan identiti kebangsaan yang utuh dan budaya penyayang. Selain itu juga, bakat rakyat turut dikenal pasti sebagai aspirasi bagi membentuk negara Malaysia yang maju iaitu melalui personaliti yang memberi inspirasi. Rakyat dilihat sebagai salah satu komponen organisasi masyarakat dan bangsa haruslah diuruskan sebaiknya dan melalui Rancangan Malaysia ini, ia menunjukkan bahawa komitmen kerajaan dalam menjaga dan menghargai rakyat selaku 'aset' negara yang berharga. Rakyat berkeyakinan tinggi, mempunyai kecerdasan emosi dan rohani serta mampu berkomunikasi dengan 
berkesan dan memiliki daya kepimpinan yang boleh memberi inspirasi kepada masyarakat dalam dan luar negara untuk mencapai kecemerlangan (RMK 11 Bab 10 Malaysia Pasca 2020, 2016: 9).

Melihat kepada kesinambungan dalam beberapa siri Rancangan Malaysia yang telah dirangkakan oleh pihak kerajaan, pembinaan identiti individu, masyarakat lantas bangsa itu sendiri sangat relevan untuk diteruskan mengikut kesesuaian yang diperlukan bertepatan dengan perubahan semasa yang berlaku dalam kehidupan seharian. Bagi memastikan kelangsungan survival sesebuah bangsa, ia amat bergantung kepada keupayaan sesebuah bangsa memiliki khazanah yang disebut manfaat segala bentuknya; kekuatan intelektual, moral dan material yang semunaya didasari semangat kebaktian kemanusiaan (Siddiq Fadzil, 2012: 7). Amat malang jika sesebuah negara itu berdaya saing pada peringkat antarabangsa dan terkenal seantero dunia tapi pada hakikat masyarakat di negara tersebut telah kehilangan identiti mereka sendiri. Mereka menjadi masyarakat yang mementingkan diri sendiri, tiada nilai kemanusiaan serta hilang kesantunan dari segi berbahasa. Bagi bangsa Melayu selaku masyarakat yang mempunyai majoriti dan menjadi tulang belakang utama kepada negara Malaysia, mereka inilah yang menjadi cerminan utama kepada mata-mata pemerhati yang datang dari luar negara sama ada tujuan rasmi atau pun bersantai bagi menterjemahkan identiti negara Malaysia pada amnya dan bangsa Melayu secara khususnya.

Karya yang memperincikan kehebatan bangsa Melayu seperti Hikayat Hang Tuah cuba menghidupkan semula kegemilangan bangsa Melayu selepas kerajaan Melaka dikalahkan oleh Portugis (Hassan Ahmad, 2004), menggambarkan betapa hebatnya bangsa Melayu. Raja yang menjadi lambang kedaulatan bangsa Melayu, Bendahara pula melambangkan kebijaksanaan dalam mentadbir kerajaan pada ketika itu manakala kekuatan Hang Tuah mencerminkan kekuatan tentera Tanah Melayu pada zaman Kesultanan Melaka. Watak-watak ini tidak dimatikan pada akhir penceritaan karya ini yang mana tujuannya adalah menyampaikan kepada pembaca bahawasanya bangsa Melayu tidak akan sesekali hilang ditelan dunia. Melalui karya-karya Kesusasteraan Melayu, dapat digambarkan bagaimana perkembangan, pembinaan malahan juga kemerosotan sesebuah bangsa.

Di samping itu, Dasar Kebudayaan Kebangsaan yang telah diperkenalkan oleh Tun Abdul Razak pada ketika beliau menyandang jawatan sebagai Perdana Menteri pada tahun 1971 adalah merupakan satu inisiatif yang diambil oleh pihak kerajaan bagi dijadikan garis panduan dalam membentuk, menwujud dan mengekalkan identiti negara dalam kalangan dunia antarabangsa. Penggubalan dasar ini juga telah melalui proses yang sangat rapi apabila ia dirangka dengan berhati-hati supaya fakta-fakta perkembangan sejarah di rantau ini serta kedudukan Malaysia selaku titik pertemuan aktiviti perdagangan pada zaman dahulu dipelihara. Proses Pertemuan ini telah menwujudkan proses interaksi, pengenalan, penyerapan dan penerimaan pelbagai unsur-unsur yang sesuai kepada kebudayaan asas rantau ini daripada pelbagai unsur-unsur kebudayaan dunia (Ayu Nor Azilah Mohamad, Rohaini Amin \& Nor Azlina Endut, 2017: 2).

Tiga prinsip telah ditetapkan menjadi tunjang kepada Dasar Kebudayaan Kebangsaan adalah berteraskan kebudayaan rakyat asal rantau ini, unsur-unsur kebudayaan lain yang sesuai dan wajar diterima serta Islam menjadi unsur yang terpenting dalam pembentukan kebudayaan kebangsaan (Dasar Kebudayaan Kebangsaan, 1971). Walaupun telah hampir setengah abad diperkenalkan, haruslah diakui bahawa pihak kerajaan masih lagi perlu berusaha keras agar segala objektif dan strategi-strategi dilaksanakan dengan jayanya. Sememangnya dasar yang digubal oleh kerajaan pada ketika itu sangat penting bagi proses pembangunan Malaysia di mana identiti Malaysia itu haruslah dibentuk agar pembangunan dari segi sosioekonomi dan politik dipertingkatkan. Segala perancangan berbentuk kebudayaan di negara kita juga haruslah menentukan sifat-sifat yang baik, mulia dan utama bagi memastikan pembinaan bangsa dan ketahanan bangsa. Keupayaan ketiga-tiga prinsip Dasar Kebudayaan Kebangsaan mengangkat identiti bangsa haruslah dilakukan secara berterusan. Namun begitu, dasar ini seolah-olah hanya tertulis sahaja di atas kertas dan proses perlaksanaannya semakin dilupakan.

Sehubungan dengan itu, kajian ini bakal melihat bagaimanakah pembinaan identiti bangsa Melayu melalui bidang Kesusasteraan Melayu yang dilihat sebagai satu medium menterjemahkan identiti 
sesebuah bangsa melalui watak dan perwatakan yang ditonjolkan oleh pengarang iaitu Hamka. Ini kerana proses pembinaan identiti oleh watak dan perwatakan serta masyarakat yang melatari ketigatiga novel ini adalah refleksi kepada pembinaan dan pembentukan identiti bangsa Melayu secara realiti. Disiplin pengurusan pula diguna pakai dalam melihat bagaimana tiga watak utama yang dipilih menguruskan elemen-elemen yang mempengaruhi bagi pembinaan sebuah identiti yang kukuh.

\section{METODOLOGI}

Kajian ini merupakan kajian kualitatif yang menggunakan kaedah kepustakaan dan kaedah analisis teks kandungan (content analysis). Kaedah ini akan mengumpul dan menganalisis data isi kandungan teks tiga buah novel karya Hamka iaitu Tenggelamnya Kapal Van Der Wijck, Merantau ke Deli dan Di Bawah Lindungan Ka'bah. Watak dan perwatakan tonggak utama dalam ketiga-tiga buah novel ini akan diteliti dalam merungkai pengurusan identiti yang telah diketengahkan oleh Hamka.

Bagi menjalankan kajian ini, dua teori akan digunakan iaitu Teori Teksdealisme dan 14 Prinsip Pengurusan Henry Fayol. Teori Teksdealisme merupakan gagasan teori yang diperkenalkan oleh Prof. Madya Dr. Abdul Rahman Hanapiah atau lebih dikenali sebagai Mana Sikana yang akan menjadi teori induk dalam kajian ini manakala 14 Prinip Pengurusan oleh Henry Fayol pula adalah sebagai teori sokongan. Dua prinsip dalam Teori Teksdealisme iaitu prinsip kehadiran dan prinsip pelanggaran diaplikasikan bagi melihat proses pembinaan identiti yang unggul dalam ketiga-tiga buah novel pilihan. Teori ini juga digunakan bagi melihat kepengarangan seorang pengarang itu pada hakikatnya mampu mengangkat sesebuah teks menjadi sebuah karya unggul dengan menyentuh dan mempengaruhi hati serta emosi pembaca. Justeru itu dengan menguna pakai konsep yang sama iaitu bagi membina keunggulan, ia dilihat dapat mempengaruhi pembentukan identiti individu pembaca yang merupakan salah satu dari komponen yang membentuk komuniti masyarakat dan bangsa beridentiti unggul.

Seterusnya, dalam menyokong penelitian terhadap identiti bangsa Melayu ini, kajian ini juga menggunakan 14 Prinip Pengurusan oleh Henry Fayol. Ia bertujuan bagi mengukuhkan analisis dan dapatan kajian dalam menyentuh pembentukan dan pembinaan identiti bangsa Melayu melalui sudut pengurusan. Henry Fayol melalui penulisan eksekutifnya yang bertajuk General and Industrial Management telah banyak dijadikan rujukan dalam hal-hal pengurusan dan pentadbiran. Pelopor berasal dari Perancis juga terkenal apabila beliau mengemukakan 14 prinsip ini yang rata-ratanya telah menjadi menjadi panduan dan rujukan dalam urus tadbir. Kesemua prinsip ini akan diteliti sama ada adakah ia diterapkan dan diaplikasi oleh ketiga-tiga watak utama yang telah dipilih dari novel-novel Hamka dalam plot penceritaan yang diolah oleh pengarang. Jadual 1 menyenaraikan 14 prinsip yang telah diperkenalkan oleh Henry Fayol.

JADUAL 1: 14 Prinsip Pengurusan Henry Fayol (sumber: Aizzat Mohd Nasurdin, Intan Osman dan Zainal Ariffin Ahmad, 2006)

\begin{tabular}{|c|c|c|}
\hline Bil. & Prinsip & Ulasan \\
\hline 1 & Pembahagian kerja & Pengkhususan kerja yang membawa kepada kecekapan dalam kerja \\
\hline 2 & Autoriti & Hak untuk memberi arahan dan kuasa ketaatan dari pekerja \\
\hline 3 & Disiplin & Disiplin diperlukan untuk menjalankan operasi organisasi \\
\hline 4 & Uniti perintah & $\begin{array}{l}\text { Seorang pekerja patut menerima arahan daripada seorang ketua } \\
\text { sahaja }\end{array}$ \\
\hline 5 & Satu arah & $\begin{array}{l}\text { Semua aktiviti untuk mencapai objektif yang sama mesti diurus oleh } \\
\text { seorang }\end{array}$ \\
\hline 6 & $\begin{array}{l}\text { Utamakan kepentingan } \\
\text { organisasi }\end{array}$ & Kepentingan organisasi menjadi prioriti \\
\hline 7 & Pengupahan & Pemberian ganjaran mesti adil bagi pihak pekerja dan majikan \\
\hline 8 & Pemusatan & $\begin{array}{l}\text { Objektif pemusatan atau pemencaran ialah untuk penggunaan } \\
\text { kebolehan personel yang optimum }\end{array}$ \\
\hline 9 & Rantaian skala & $\begin{array}{l}\text { Skala rantaian autoriti (hirarki) dan laluan komunikasi dari atas ke } \\
\text { bawah dan juga mendatar }\end{array}$ \\
\hline
\end{tabular}


11 Ekuiti

12 Kestabilan perkhidmatan personel

13 Inisiatif

14 Semangat kekitaan
Semua bahan dan sumber tersimpan di tempat tertentu begitu juga manusia dalam jawatan yang secocok dengannya

Pekerja dilayan dengan adil

Pengurangan lantik henti dan pengekalan pekerja dilakukan

Menggalakkan pekerja mengambil inisiatif

Harmoni dan kerja berpasukan amat tinggi

Terdapat empat aspek yang dilihat mempengaruhi pembinaan identiti bangsa Melayu adalah budaya yang merujuk kepada nilai norma yang dipegang, imej yang menggambarkan imej tradisi, bahasa yang merujuk kepada bahasa pengantar yang digunakan dalam kehidupan seharian dan kemudiaanya adalah agama yang merujuk kepada akhlak yang sempurna. Penyatupaduan keempat aspek ini adalah dilihat menjadi tunjang kepada identiti bangsa Melayu. Aspek-aspek ini akan dianalisis dengan melihat bagaimanakah keempat-empat tunjang ini diuruskan oleh watak-watak utama yang telah dipilih. Ketika inilah disiplin pengurusan diterapkan dalam melihat proses pengorganisasian yang dilakukan oleh watak-watak tersebut bagi membina dan membentuk identiti mereka.

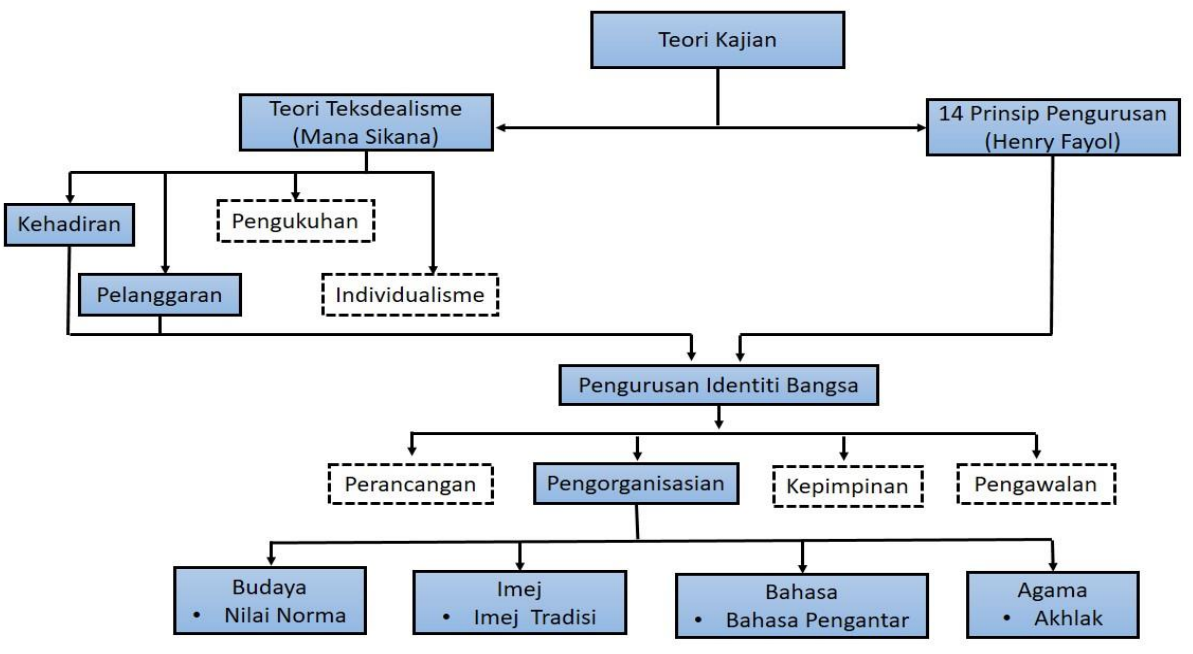

RAJAH 1: Kerangka Kajian

Proses pengumpulan data bagi kajian ini adalah bersumberkan kajian kepustakaan kerana keseluruhan bahan yang terlibat di dalam kajian ini adalah daripada buku-buku, majalah, jurnal, artikel dan kajiankajian di peringkat pasca siswazah dan sebagainya. Sumber utama bagi kajian ini ataupun data primer adalah merupakan ketiga-tiga novel pilihan karya Hamka iaitu Tenggelamnya Kapal Van Der Wijck (2015), Merantau ke Deli (2015) dan Di Bawah Lindungan Ka'bah (2015) yang diterbitan oleh PTS Publications \& Distributors Sdn. Bhd. Bagi data sekunder yang terlibat dalam kajian ini pula adalah buku-buku, majalah, artikel, jurnal, al-Quran dan al-Hadis yang membincangkan ruang lingkup bidang kajian serta dilihat mampu memberi kekuatan serta fakta dalam menyokong analisis, perbincangan, cadangan serta hujahan di dalam kajian ini. Data yang akan di analisis di dalam kajian ini adalah kesemua watak utama yang dibina oleh Hamka di dalam ketiga-tiga buah novel pilihan iaitu Tenggelamnya Kapal Van Der Wijck (TKVDW), Merantau ke Deli (MKD) dan Di Bawah Lindungan $K a$ 'bah $(D B L K)$. Antara watak-watak yang terlibat yang akan dianalisis dalam kajian ini adalah; 
JADUAL 2: Watak utama yang dipilih untuk dianalis

\begin{tabular}{lll}
\hline Novel Pilihan & \multicolumn{2}{l}{ Watak-Watak Yang Akan Dianalisis } \\
\hline Tenggelamnya Kapal Van Der Wijck & $\bullet$ & Zainuddin \\
Merantau ke Deli & $\bullet$ & Poniem \\
Di Bawah Lindungan Ka'bah & $\bullet$ & Hamid \\
\hline
\end{tabular}

\section{Kaedah Analisis Data}

Bagi proses menganalisis data di dalam kajian ini, teks pilihan iaitu novel TKVDW, MKD dan DBLK akan dibaca secara keseluruhan dan mendalam bagi mengenal pasti watak serta memahami perwatakan binaan Hamka dalam jalinan dan jalan penceritaan. Ia a bertujuan bagi memahami ciri-ciri masyarakat Melayu yang digambarkan oleh Hamka pada zaman tersebut. Apabila ciri-ciri masyarakat Melayu secara perseorangan yakni melalui setiap watak yang ditonjolkan oleh Hamka dikenal pasti dan difahami, secara tidak langung ia membawa pemahaman terhadap identiti yang dapat dibentuk oleh komuniti masyarakat Melayu pada ketika itu. Empat ciri-ciri yang dilihat mempengaruhi pembinaan identiti bangsa Melayu iaitu budaya (nilai norma), imej (tradisi), bahasa (bahasa pengantar) dan agama (akhlak).

Disiplin pengurusan yang diterap dan diamalkan oleh watak-watak dalam mengharungi setiap peristiwa-peristiwa serta konflik di dalam plot penceritaan novel-novel tersebut diteliti apabila mereka mengorganisasikan keempat-empat elemen iaitu budaya, imej, bahasa dan Agama dalam membentuk satu identiti yang unggul. Sebagaimana menurut Bartol dan Martin (1994) mendefinisikan pengorganisasian sebagai proses mengagihkan dan menyusun sumber manusia dan bukan manusia supaya pelan dapat dilaksanakan dengan jayanya. Maka, dengan menerapkan konsep pengorganisasian di atas, kajian ini akan mengaplikasikan prinsip pengorganisasian dengan melihat bagaimanakah watakwatak utama ini menyusun elemen budaya, imej, bahasa dan agama dalam membina satu identiti bangsa Melayu yang unggul. Selain itu juga, 14 prinsip pengurusan oleh Henry Fayol dilihat satu persatu dan dipastikan elemen yang manakah mengunakan 14 prinsip tersebut.

Di samping watak serta perwatakan, nilai dan pengajaran yang cuba disampaikan oleh pengarang juga dirungkai kerana dalam setiap peristiwa atau pun konflik terdapat kesan yang memberi bekas kepada pada watak-watak utama ini. Kesan tersebut telah merubah secara tidak langsung watak dan perwatakan mereka menjadi seorang yang lebih baik dan memupuk mereka membina satu persamaan identiti yang lebih kukuh. Ketika melakukan proses analisis ini, pemilihan data atau pengurangan data dilakukan dengan mengabaikan data yang tidak penting ataupun tidak relevan dalam mencapai objektif kajian dan menjawab soalan kajian. Data yang berkaitan diberi penekanan dan akan dikeluarkan untuk dicerakinkan bagi dianalisis serta dibincangkan.

\section{ANALISIS PENGURUSAN IDENTITI BANGSA}

Meneliti pembinaan identiti bangsa Melayu dalam kajian ini adalah dengan mengambil kira sudut pengurusan sebagai disiplin bagi melihat bagaimanakah watak serta perwatakan yang dibina oleh Hamka dalam ketiga-tiga novel ini mengorganisasikan identiti mereka melalui segala peristiwa dan konflik yang dihadapi. Empat elemen yang difokuskan dalam pembinaan identiti ini ialah budaya, imej, bahasa dan agama. Prinsip pengurusan yang mempunyai empat perkara iaitu perancangan, pengorganisasian, kepimpinan dan kawalan hanyalah difokuskan kepada prinsip kedua sahaja iaitu pengorgnisasian kerana ia bertujuan melihat bagaimanakah watak-watak ini mengatur kepelbagaian ciri-ciri yang mereka punyai bagi membentuk kelompok bangsa Melayu yang beridentiti. Setiap bangsa 
sudah tentu mempunyai matlamat mereka tersendiri dan sudah pasti dalam mencapai matlamat tersebut, mereka harus mempunyai kesepaduan dalam membentuk dan mencapai matlamat tersebut. Kesepaduan ini akan diperoleh melalui proses pengorganisasian yang teratur. Sudah tentu ia harus dimulai dengan memiliki satu identiti yang diuruskan dengan baik.

Keempat-empat prinsip asas pengurusan tidak dilihat secara lebih mendalam secara keseluruhannya kerana kajian ini menumpukan kepada prinsip yang dilihat memainkan peranan yang dilihat sebagai dominan dan mempunyai hubungan yang signifikan sahaja. Keupayaan seseorang individu yakni watak utama yang dibina oleh Hamka iaitu Zainuddin, Poniem dan Hamid mengorganisasikan kebolehan serta keistimewaan yang mereka peroleh dalam menjalani kehidupan dan menghadapi segala permasalahan dalam kehidupan membolehkan mereka mencapai matlamat dalam kehidupan dan bangkit dari kesulitan serta dugaan dalam kehidupan mereka. Pada akhirnya, segala bentuk nilai dan pengajaran yang telah mereka peroleh membentuk satu jati diri atau identiti mereka sendiri tanpa dipengaruhi oleh orang lain. Berlakunya perubahan kepada ketiga-tiga watak utama ini selepas sesuatu isu atau peristiwa ternyata boleh dikesan oleh pembaca selepas mereka berjaya menghadapi serta menangani sesuatu isu atau konflik.

Mengaplikasikan Teori Teksdealisme oleh Mana Sikana yang melihat kepada kepengarangan seseorang pengarang dalam membina keunggulan mereka sendiri serta teks yang dihasilkan adalah kerana mempercayai bahawa sesebuah karya yang unggul dapat memberikan impak yang besar kepada para pembaca. Konsep yang sama juga digunakan dalam kajian ini bagi melihat bagaimanakah pembentukan sebuah identiti masyarakat yang unggul melalui pembinaan watak-watak utama dalam novel tersebut oleh Hamka. Pada ketika menghasilkan karya, watak-watak ini kebiasaannya adalah hasil idea berdasarkan pengalaman ataupun pengamatan penulis terhadap kejadian yang berlaku di sekeliling mereka. Maka, kebanyakan watak, plot penceritaan dan latar masyarakat adalah sama dengan realiti yang sebenar dalam kehidupan seharian.

Pelanggaran pula dapat dilihat apabila pengarang cuba melakukan perubahan kepada watak dan perwatakan pendokong utama tersebut. Perubahan ini dapat dikesan oleh pembaca apabila terdapat perubahan ketara terhadap watak Zainudin (TKVDW), Poniem (MKD) dan Hamid (DLK). Di sinilah berlakunya pertembungan yang sudah tentu menarik minat pembaca bagi terus menghayati jalan penceritaan oleh pengarang serta menjadikan jalan cerita sesebuah karya menarik. Kedua-dua prinsip Teksdealisme ini boleh dikatakan adalah 'nyawa' dan 'jantung' kepada proses penghasilan karya yang menarik. Sudah pasti karya yang menarik akan didokong oleh watak-watak utama yang mempunyai perwatakan iaitu identiti yang unggul.

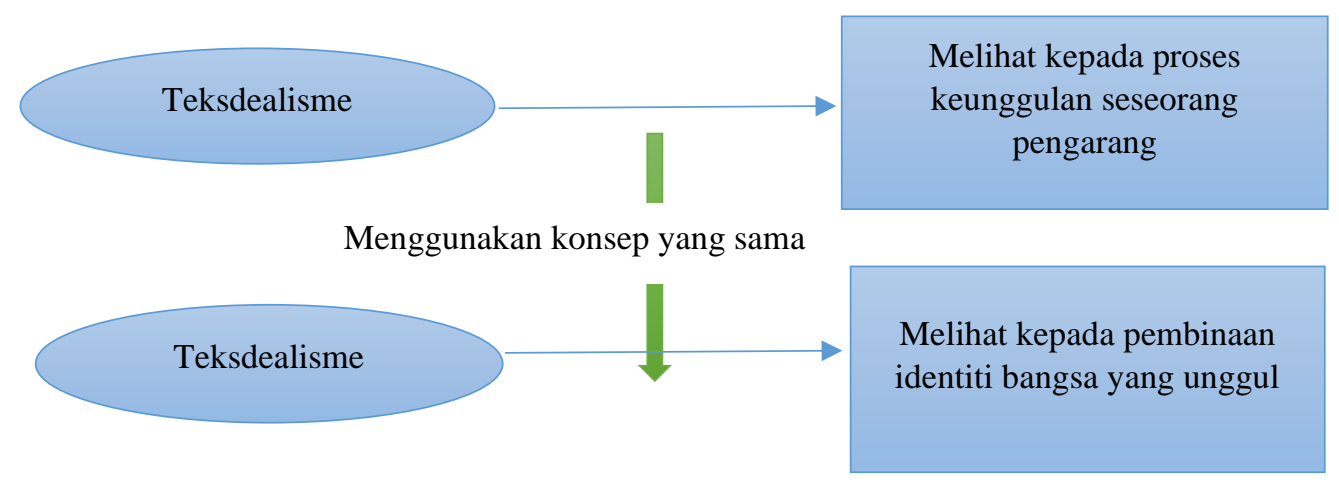

RAJAH 2: Pengaplikasian Konsep Teksdealisme

Pengukuhan analisis kajian yang menjadikan 14 Prinsip Pengurusan oleh Henry Fayol sebagai teori dokongan dalam menguatkan lagi analisis dan perbincangan bagi pembentukan identiti Melayu dilihat mampu menjadikan dapatan kajian ini adalah lebih kukuh. Pengalaman Fayol sebagai seorang jurutera perlombongan, ahli perniagaan dan pengurus yang berjaya telah diakui merupakan seorang pengasas 
Teori Pengurusan Klasik. Pengalamannya yang begitu luas dan mendalam selama beliau terlibat dalam aspek pengurusan telah membuktikan bahawa kepentingan dan keperluan kesemua 14 prinsip ini diterapkan serta dijadikan panduan bagi mengurus sesebuah organisasi. Oleh itu, organisasi sesebuah bangsa juga merupakan satu entiti yang wajar diuruskan dengan baik agar ia dapat membangun dan berkembang bagi mencapai wawasan bangsa tersebut pada masa hadapan. Pemilihan landasan teori yang merujuk kepada teori sastera dan teori pengurusan dilihat amat relevan bagi penelitian ini agar hasil dapatan adalah lebih konkrit dan seimbang.

Berdasarkan novel-novel pilihan karya Hamka yang telah dipilih ini, ketiga-tiga watak utama telah memainkan peranan yang sangat dominan dalam memberi impak yang besar kepada jalan penceritaan olahan pengarang. Watak-watak utama ini telah membuktikan bahawa kesemua 14 Prinsip Pengurusaan janaan Henry Fayol telah diaplikasikan secara sepenuhnya. Keempat belas prinsiptersebut telah membentuk dan menjadikan watak-watak utama ini iaitu Zainuddin, Poniem dan Hamid mempunyai identiti kukuh sebagai seorang masyarakat Melayu dan bangsa Melayu yang bertunjangkan budaya, imej, bahasa dan agama sebagai landasan utama dalam menjalani kehidupan mereka.

\section{PENUTUP}

Pembinaan identiti bangsa Melayu memang banyak diperkatakan dan telah dirungkai oleh para pengkaji sebelumnya kerana iamerupakan sudut sisi yang penting dalam memahami bangsa Melayu. Dalam merangka, merancang dan memahami pembentukan identiti ini, wajarlah jika memahami dan mengenali bangsa Melayu ini melalui penelitian-penelitian dan penulisan-penulisan yang sebelumnya. Sememangnya kajian ini adalah ingin mengkaji pembentukan identiti pada masa kini, namun dalam masa yang sama kita masih perlu untuk melihat yang lama dalam membina satu identiti yang kukuh dan unggul pada masa hadapan. Maka, pemilihan ketiga-tiga novel garapan Hamka dalam kajian ini dilihat adalah sangat sesuai berdasarkan latar belakang penulis itu sendiri iaitu seorang pejuang bangsa dan tokoh ilmuan agama.

Sesungguhnya sastera merupakan seimograf kehidupan pada keadaan realiti diterjemahkan oleh pengarang melalui penulisan menarik dan gaya bahasa yang indah. Disiplin pengurusan yang melihat sudut pengorganisasian dalam membina identiti yang unggul melalui pembinaan watak-watak iaitu Zainuddin, Poniem dan Hamid adalah merupakan jelmaan watak sebenar kepada individu-individu yang terdapat dalam kehidupan tidak kira pada masa dahulu atau sekarang. Keunggulan pengarang yang terbina melalui beberapa proses atau tahap dilihat seakan proses bagi seseorang individu atau kelompok bangsa membina identiti masing-masing. Maka, mengaplikasikan konsep Teori Teksdealisme dalam melihat pembinaan identiti yang unggul bagi bangsa Melayu adalah sangat bersesuaian.

Dokongan dari 14 Prinsip Pengurusan oleh Henry Fayol yang melihat kepada bagaimana pentingnya sesebuah organisasi itu seharusnya mempunyai pegangan untuk dijadikan panduan bagi memastikan segala aspek pengurusan bagi membentuk sebuah komuniti yang disegani kerana keteguhan identitinya yang terpelihara malahan terus dibajai agar sentiasa terus berkembang dalam bergerak seiring dengan arus modenisasi semasa. Diharapkan penulisan makalah ini yang merupakan suatu pengenalan kepada kajian yang dijalankan dapat dimantapkan dari semasa ke semasa melalui diskusi dan pandangan daripada sarjana-sarjana tempatan mahupun antarabangsa.

\section{RUJUKAN}

Aizzat Mohd Nasurdin, Intan Osman dan Zainal Ariffin Ahmad. (2006). Pengantar Pengurusan. Kuala Lumpur: Utusan Publications \& Distributors Sdn. Bhd.

Ahmad Fawzi Mohd. Basri, Abdul Rahman Abdul Aziz dan Mansor Mohd Noor. (2005). Jati Diri Melayu Dalam Politik: Suatu Tinjauan Awal. Dlm Anwar Ridhwan (peny). Minda Melayu, hlm 301-315. Kuala Lumpur: Dewan Bahasa dan Pustaka. 
Ayu Nor Azilah Mohamad, Rohaini Amin dan Nor Azlina Endut. (2017). Pemupukan Nilai-Nilai Murni Antara Etnik Di Malaysia Melalui Dasar Kebudayaan Kebangsaan. Kertas Kerja Persidangan Antarabangsa Sains Sosial dan Kemanusiaan (PASAK) Kali Ke-2. Anjuran Kolej Universiti Islam Antarabangsa Selangor. 2627 April 2017.

Bartol, Kathryn M. \& Martin, David C. (1994). Management. $2^{\text {nd }}$ ed. Amarika Syarikat: McGraw-Hill, Inc.

Certo, S.C. (1997). Modern Management. $7^{\text {th }}$ Ed. New Jersey: Prentice-Halll, Inc.

Chandri Singh dan Aditi Khatri. (2016). Principles and Practices of Management and Organizational Behaviour. India: SAGE Publications India Pvt Ltd.

Daft, R.L. (1997). Management. $4^{\text {th }}$ Ed. Orlando: The Dryden Press.

Dasar Kebudayaan Kebangsaan. 1971. Dicapai pada 2 Februari 2019 dari http://www.pmo.gov.my/dokumenattached/Dasar/04Dasar_Kebudayaan_Kebangsaan.pdf.

Farahanna Abd Razak, Ida Baizura Bahar dan Rosli Talif. (2016). Emerging Patterns of Bangsa Malaysia in Anthony Burgess' Time For A Tiger. Dlm International Journal of Applied Linguistics \& English Literature, Vol. 5 No. 1; Januari 2016. Hlm 264-271.

Hassan Ahmad. (2004). Bahasa dan Pemikiran Melayu: Tradisi dan Kesinambungannya. Dlm Worawit Baru @ Haji Ahmad Idris (peny). Pemikiran Melayu Tradisi dan Kesinambungan, hlm 1-12. Kuala Lumpur: Dewan Bahasa dan Pustaka.

Hasni Zakaria dan Novel Lyndon. (2014). Identiti Budaya dan Bahasa Etnik Melayu Thesaban Takbai, Selatan Thailand: Satu Analisa Fenomenologi. Dlm Malaysian Journal of Society and Space 10 issue 6 (148 - 155).

Hamka. (2015). Di Bawah Lindungan Ka'bah. PTS Publications \& Distributors Sdn. Bhd.: Kuala Lumpur.

Hamka. (2015). Merantau Ke Deli. PTS Publications \& Distributors Sdn Bhd; Kuala Lumpur.

Hamka. (2015). Tenggelamnya Kapal Van Der Wijck. PTS Publications \& Distributors Sdn. Bhd.: Kuala Lumpur. Kamus Dewan. 1994. Kuala Lumpur: Dewan Bahasa dan Pustaka.

Laurent Metzger. (2009). Nilai-nilai Melayu Satu Sudut Pandangan Orang Luar. Tanjong Malim: Penerbit Universiti Pendidikan Sultan Idris.

Lia Dwi Purwanti. (2016). Nilai-Nilai Pendidikan Sosial Dalam Novel Tenggelamnya Kapal Van Der Wijck Karya Buya Hamka. Tesis Ijazah Sarjana Jurusan Pendidikan Agama Islam Fakultas Tarbiyah Dan Ilmu Keguruan: Institut Agama Islam Negeri (Iain) Salatiga

Mana Sikana. (2015). Teori Sastera Kontemporari. Selangor: Pustaka Karya.

Mana Sikana. (2004). Sastera Melayu Pascamodenisme. Kuala Lumpur: Dewan Bahasa dan Pustaka.

Manuel Castells. (1997). The Power of Identity. Massachusetts: Blackwell Publishers.

Mohamad Mokhtar Abu Hassan. (2013). Pendekatan Pengurusan: Satu Metode Dalam Kritikan Sastera. Himpunan Ilmuwan Sastera Melayu Malaysia Kedua, Universiti Pendidikan Sultan Idris, 4-5 Oktober 2013.

Mohamad Saleeh Rahamad. (2012). Pewacanaan Identiti Bangsa dalam Sastera Selepas Medeka: Pengalam Malaysia. Kertas Kerja Konferentasi Internasional Keusasteraan XXII-UNY-HISKI. Anjuran Fakultas Bahasa dan Seni, Universitas Negeri Yogyakarta. November 2012.

Mohamad Zubir Ismail, Sara Beden \& Mohamad Mokhtar Hassan. (2015). Hikayat Awang Sulung Merah Muda Dari Perspektif Pendekatan Pengurusan. Dlm Jurnal Pengajian Melayu, Jilid 26, 2015, hlm 95-116.

Mohamad Zubir Ismail \& Mohamad Mokhtar Hassan. (2017). Prinsip Perancangan Dalam Hikayat Awang Sulung Merah Muda. Dlm Journal of Business and Social Development, Volume 5 Numbor 1, Mac 2017: 123139.

Muhammad Hilmi Jalil dan Fakhrul Adabi Abdul Kadir. (2012). Comprehensive Human Development Through Physical And Spiritual: Studies On The Novel "Tenggelamnya Kapal Van Der Wijck". Dlm Procedia Social and Behavioral Sciences 55 ( 2012 ), hlm 1118 - 1123.

Nurul Izzah Sidek. (2011). Remaja dan Krisis Identiti. Utusan Malaysia Online. Dicapai pada 11 Disember 2016 dari

http://ww1.utusan.com.my/utusan/info.asp?y=2011\&dt=1103\&pub=Utusan_Malaysia\&sec=Bicara_Aga ma\&pg=ba_05.htm\#ixzz4XZy24CyZ @ Utusan Melayu (M) Bhd.

Perlembagaan Malaysia. (2009). Dicapai pada 8 November 2018 dari http://www.kptg.gov.my/images/pdf/perundangantanah/perlembagaanpersekutuan.pdf

Rancangan Malaysia Ke Sebelas, 2016-2020: Bab 1 Pertumbuhan Berpaksikan Rakyat. Dicapai pada 8 November 2018 dari http://epu.gov.my/ms/rmk/rancangan-malaysia-kesebelas-2016-2020

Rancangan Malaysia Ke Sebelas, 2016-2020: Bab 5 Meningkatkan Pembangunan Modal Insan Untuk Negara Maju. Dicapai pada 8 November 2018 dari http://epu.gov.my/ms/rmk/rancangan-malaysia-kesebelas2016-2020. 
Rancangan Malaysia Ke Sebelas, 2016-2020: Bab 10 Malaysia Pasca 2020. Dicapai pada 8 November 2018 dari http://epu.gov.my/ms/rmk/rancangan-malaysia-kesebelas-2016-2020

Reicher S. \& Hopkins N. (2001). Self And Nation. London: Sage Publications Ltd.

Robbins, Stephen P. \& Coutler, Mary. (2005). Management. $8^{\text {th }}$ Ed. New Jersey: Pearson Education, Inc.

Siddiq Fadzil. (2012). Islam dan Melayu: Martabat Umat dan Daulat Rakyat. Selangor: Gemilang Press Sdn. Bhd.

Smith, Anthony D. (1998). Nationalism and Modernism. Abingdon UK: Routledge.

Sukatan Pelajaran STPM Baharu 922 Kesusasteraan Melayu Komunikatif. Dicapai pada 8 November 2018 http://portal.mpm.edu.my/web/guest/sukatan-pelajaran-stpm-modular.

Wan Sallha Yusoff, Nurul Syazwani, Ahmad Fahmi Mahmood dan Noor Asliza Abdul Rahim. (2010). "Faktorfaktor Yang Mempengaruhi Penentuan Identiti Diri Remaja Melayu”. Kertas Kerja Seminar Pendidikan Melayu Antarabangsa, 29-31 Mac 2010 anjuran Universiti Malaysia Perlis. 